\title{
Human immunodeficiency virus prevalence in an unbooked obstetric population in the Niger Delta
}

This article was published in the following Dove Press journal:

HIVIAIDS - Research and Palliative Care

24 September 2010

Number of times this article has been viewed

\author{
Chris I Akani' \\ Erhabor Osaro 2 \\ Dennis O Allagoa' \\ 'Departments of Obstetrics and \\ Gynecology, ${ }^{2} \mathrm{Hematology,} \mathrm{University}$ \\ of Port Harcourt Teaching Hospital, \\ Port Harcourt, Nigeria
}

\begin{abstract}
Despite recent advances in the prevention of transmission of human immunodeficiency virus (HIV) infection from mother to child during pregnancy, infants continue to be born and infected with HIV, particularly in Africa. This study was undertaken to determine the seroprevalence of HIV infection among unbooked pregnant women in the Niger Delta of Nigeria. One hundred and eighteen consecutively recruited unbooked subjects presenting to the isolation ward at the University of Port Harcourt Teaching Hospital were screened for HIV. Among the 118 subjects studied, 30 (25.4\%) were positive for HIV. HIV-1 was the predominant viral strain. Gestational age of subjects at presentation was 28-40 weeks and mean age was $35.04 \pm 8.06$ years. The majority of subjects were primigravidas $66(55.9 \%)$, while $52(44.1 \%)$ were multigravidas. The prevalence of HIV was significantly higher among unbooked pregnant women with less formal education: 14 (11.9\%) compared with $9(7.6 \%), 5(4.2 \%)$, and $2(1.7 \%)$ for those with primary, secondary, and tertiary education, respectively $(P=0.01)$. Among the occupational groups, the prevalence of HIV was significantly higher among traders $14(11.9 \%)$ than in career women $5(4.2 \%, P=0.04)$. Multigravid women were more susceptible to HIV infection $17(14.4 \%)$ than primigravid women. Perinatal mortality and emergency cesarean section was high among unbooked pregnant women. The prevalence of HIV observed amongst unbooked antenatal subjects in this study is significantly higher than those of booked patients in previous studies. These findings are very pertinent to health care delivery, because this pool of unbooked patients may not be benefiting from the Prevention of Maternal to Child Transmission program, thus increasing the pediatric HIV burden in our environment.
\end{abstract}

Keywords: human immunodeficiency virus, Niger Delta, Nigeria, pregnant women

\section{Introduction}

Organized preventive screening programs for antenatal care were first introduced in Western Europe in the twentieth century with the hope that routine antenatal care would contribute to a reduction in maternal and infant mortality rates. Figures on maternal mortality in the developed world show that the risk of death as a result of pregnancy and child birth is approximately 1 in 7000 compared with 1 in 23 for women living in parts of Africa where antenatal care is poor or nonexistent. ${ }^{1}$ The human immunodeficiency virus (HIV) pandemic is one of the most serious health crises faced by the world today. An estimated 33.4 million people were living with HIV/acquired immunodeficiency syndrome as at 2009. ${ }^{2}$ The prevalence of HIV in Nigeria has risen from $1.8 \%$ to $5.0 \%$ in $2003 .{ }^{3}$ A disproportionate burden has been placed on women and children, who in many settings continue to experience high rates of new HIV infection and HIV-related illness and death. Most children living with HIV acquire the infection
Correspondence: Erhabor Osaro Blood Sciences Department, Royal Bolton Hospital, Bolton, Lancashire, UK Email n_osaro@yahoo.com 
through mother-to-child transmission (MTCT), which can occur during pregnancy, labor, delivery, or breastfeeding. In the absence of any intervention, the risk of such transmission is $15 \%-30 \%$ in nonbreastfeeding populations. Breastfeeding by an infected mother increases the risk by 5\%-20\% to a total of $20 \%-45 \%{ }^{4}$ The risk of MTCT can be reduced to less than $2 \%$ by interventions that include antiretroviral prophylaxis given to women during pregnancy and labor and to the infant in the first weeks of life, during elective cesarean delivery (prior to the onset of labor and rupture of membranes), and avoidance of breastfeeding. ${ }^{5}$ With these interventions, new HIV infections in children are becoming increasingly rare in many parts of the world, particularly in high-income countries. In many resource-constrained settings, elective cesarean delivery is seldom feasible, ${ }^{7}$ and it is often neither acceptable nor safe for mothers to refrain from breastfeeding. However, recent guidelines from the World Health Organization ${ }^{6}$ recommend that mothers known to be HIV-infected (and whose infants are HIV-uninfected or of unknown HIV status) should exclusively breastfeed their infants for the first six months of life, introducing appropriate complementary foods after that. Breastfeeding should then be stopped only when a nutritionally adequate and safe diet without breast milk can be provided. In these settings, efforts to prevent HIV infection in infants initially focused on reducing MTCT around the time of labor and delivery. The unknown HIV status of these unbooked women presenting to clinic for the first time in the third trimester of pregnancy poses a risk not only to the patient and her baby, but also to the staff caring for them in the peripartum period. The baby, who is the most critical element in vertical transmission, would invariably not benefit from the prevention of mother-to-child transmission (PMTCT) HIV program, and eventually add to the bulk of pediatric HIV patients resulting in a heavy burden on their parents, health facilities, and community. In this first prospective study from the Niger Delta in Nigeria we have investigated the prevalence of HIV and birth outcomes in women who do not access any antenatal care.

\section{Materials and methods}

All pregnant women in labor admitted to the isolation ward at the University of Port Harcourt Teaching Hospital with pregnancy-related complications, or in the immediate puerperium, were counseled and written informed consent was obtained to allow for blood taking and for retroviral screening. An unbooked woman was defined as a woman presenting to clinic for the first time in the third trimester of pregnancy. The University of Port Harcourt Teaching
Hospital is a 500-bed tertiary hospital providing specialist obstetrics and gynecology services to women in the cosmopolitan city of Port Harcourt and other surrounding states of the Niger Delta in Nigeria. The hospital is one of the centers running the PMTCT program sponsored by the federal government of Nigeria. A total of 118 women were enlisted for the study. The data collected included biodata, mode of delivery, pregnancy outcome, parity, and intrapartum complications. HIV screening was carried out using a double enzyme-linked immunosorbent assay (ELISA) method, as provided in the commercially available second-generation Genscreen (Bio-Rad, France) and Immunocomb ELISA test for the qualitative and differential diagnosis of HIV (Orgenics, Israel).

\section{Statistical analysis}

Data were entered and analyzed using statistical package SPSS version 9 (SPSS Inc., Chicago, IL). Statistical analysis included descriptive analysis of mean, standard deviation, and Chi-square analysis. A $P$ value of $<0.05$ was considered to be statistically significant in all statistical analyses.

\section{Results}

Of the 118 pregnant women enlisted for this study, 30 (25.4\%) were positive for HIV. HIV-1 was the predominant viral strain. Gestational age of subjects at presentation was 28-40 weeks and mean age was $35.04 \pm 8.06$ years. The prevalence of HIV was significantly higher among pregnant women with no formal education $(\mathrm{n}=14,11.9 \%$ ) than for those with primary $(n=9,7.6 \%)$, secondary $(n=5,4.2 \%)$, or tertiary $(n=2,1.7 \%)$ education, as shown in Figure 1 . Most of the deliveries were spontaneous live births $(n=83,70.3 \%)$, with some still births $(n=2,17 \%)$ and some intrauterine fetal deaths $(n=15,12.7 \%)$, as shown in Figure 2. Vaginal delivery was the predominant mode of delivery $(n=89$, $75.5 \%$ ) among the pregnant women studied, while 29 (24.5\%) had emergency cesarean section. Among the occupational groups, the prevalence of HIV was significantly $(P=0.04)$ higher among traders $(\mathrm{n}=14,11.9 \%)$ than in career women $(\mathrm{n}=5,4.2 \%)$ as shown in Figure 3 . The majority of subjects were primigravidas 66 (55.9\%), while 52 (44.1\%) were multigravidas. Multigravid women were more susceptible to HIV infection $(\mathrm{n}=17,14.4 \%)$ compared with primigravid women $(n=13,11.0 \%)$ as shown in Figure 4.

\section{Discussion}

In this study we investigated the prevalence of HIV and pregnancy outcomes in an unbooked obstetric population in 


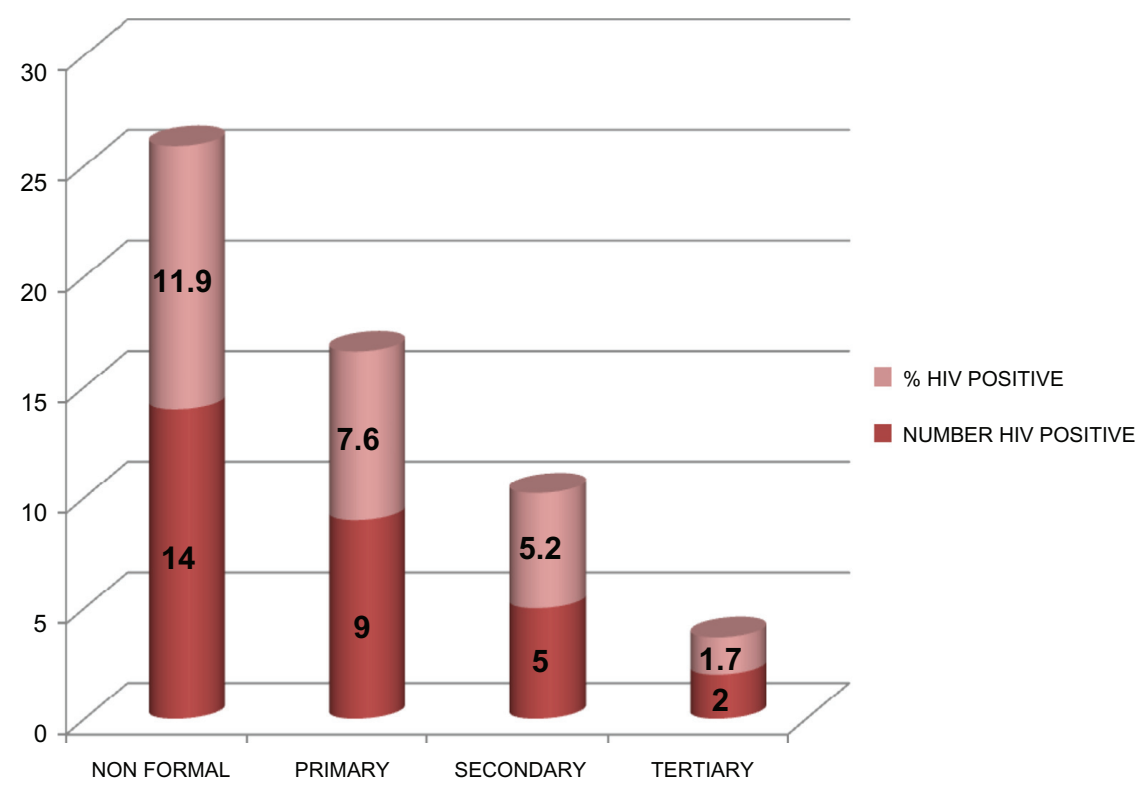

Figure I Human immunodeficiency virus prevalence among unbooked subjects based on educational status.

the Niger Delta. The overall prevalence rate observed in this study was $25.4 \%$. Our observed prevalence is significantly higher than that observed among booked antenatal subjects $(5.0 \%)$ studied in a 2003 seroprevalence sentinel survey in Nigeria. ${ }^{3}$ Counseling and detection of women infected with HIV is a difficult issue in low resource settings, where there is a high tendency for out-of-hospital births, home births, and parallel antenatal care. ${ }^{4,5}$ The pool of unbooked patients often report to appropriate health facilities late during their pregnancy with difficult labor or other disease conditions complicating their pregnancy.

The prevalence of HIV was significantly higher among unbooked patients with no formal education than in better educated subjects. The question has often arisen concerning the nature of women who are most likely to be unbooked Previous studies found that women who are homeless and addicted to illicit substances,${ }^{8}$ with a low level of education, ${ }^{9}$ low income, ${ }^{10}$ and low socioeconomic status ${ }^{11}$ are more likely to access antenatal care late or be unbooked. There may be several reasons for this association, including better educated people generally having greater access to information than those who have less formal education, and are more likely to make informed decisions and act on information given. In addition, better educated people generally have better jobs and greater access to money and other resources which can help them lead healthier lives.

We observed a higher HIV prevalence among multiparous compared with primigravid women. Previous reports ${ }^{9,12}$ have

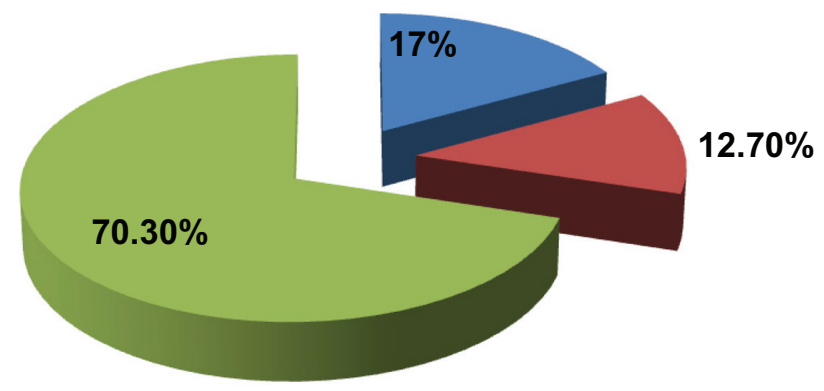

STILL BIRTH

INTRAUTERINE DEATH

LIVE BIRTH

Figure 2 Birth outcomes among unbooked subjects. 


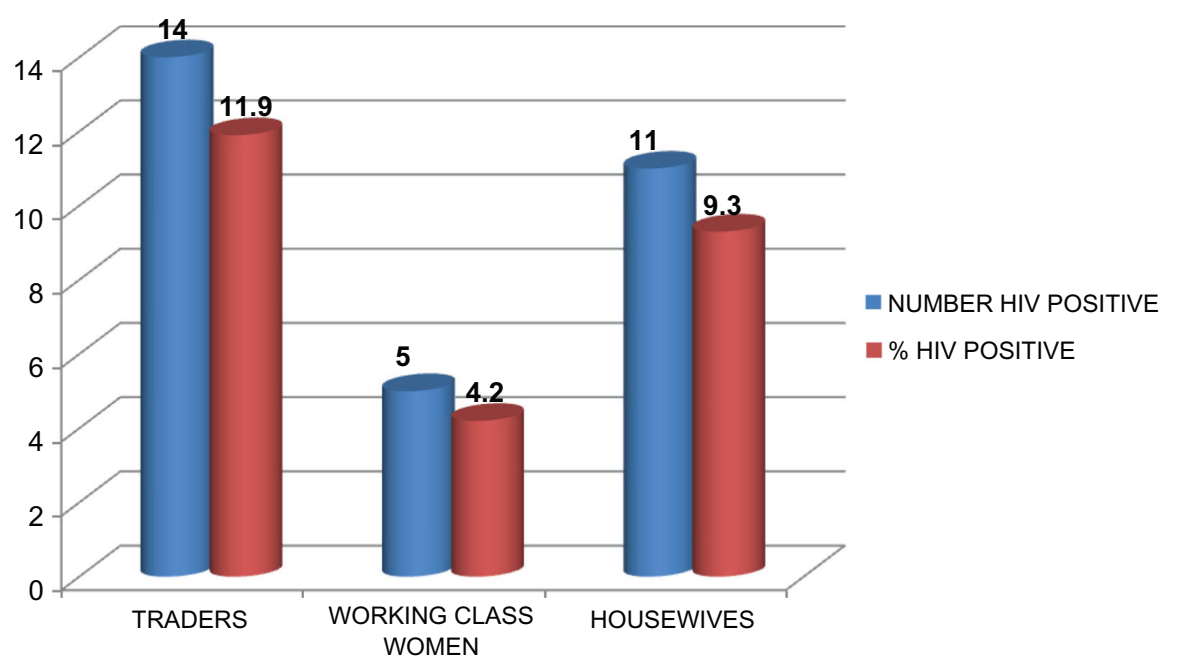

Figure 3 Human immunodeficiency virus prevalence among unbooked subjects based on ocupational groups.

suggested that a number of interrelated sociodemographic factors, including high parity, are a reason for late or poor access to antenatal services. Similarly, Shaffer in a previous report on barriers to access of antenatal care, particularly among ethnic minorities, marginalized groups and socially deprived populations with high parity has suggested that cultural issues relating to language and antenatal staff insensitivity are important, and can deter some women from accessing antenatal care early or regularly. ${ }^{13}$ Easily overlooked details, such as gender of the consulting obstetrician, can make a big difference to women's perception of antenatal services, particularly in highly religious populations. A study of Islamic women living in Australia, Tsiankasas, and Liamputtong ${ }^{14}$ found that the prospect of being given an ultrasound by a male doctor, rather than a female doctor, caused them to cancel antenatal appointments. Another study reported that Hispanic women living in the US failed to return for antenatal appointments because they felt that staff members were too rushed or simply unwilling to answer their questions. ${ }^{15}$ These cultural oversights may be viewed as disrespectful by women from various ethnic groups and have the potential to generate feelings of frustration and resentment for women in need of antenatal care. ${ }^{16}$

We observed that the majority of subjects in this study presented at a gestational age between 28 and 40 weeks, and with significantly poor birth outcomes, particularly high rates of still births (17\%), intrauterine fetal death (12.7\%), and emergency cesarean section (24.5\%). There is an increasing

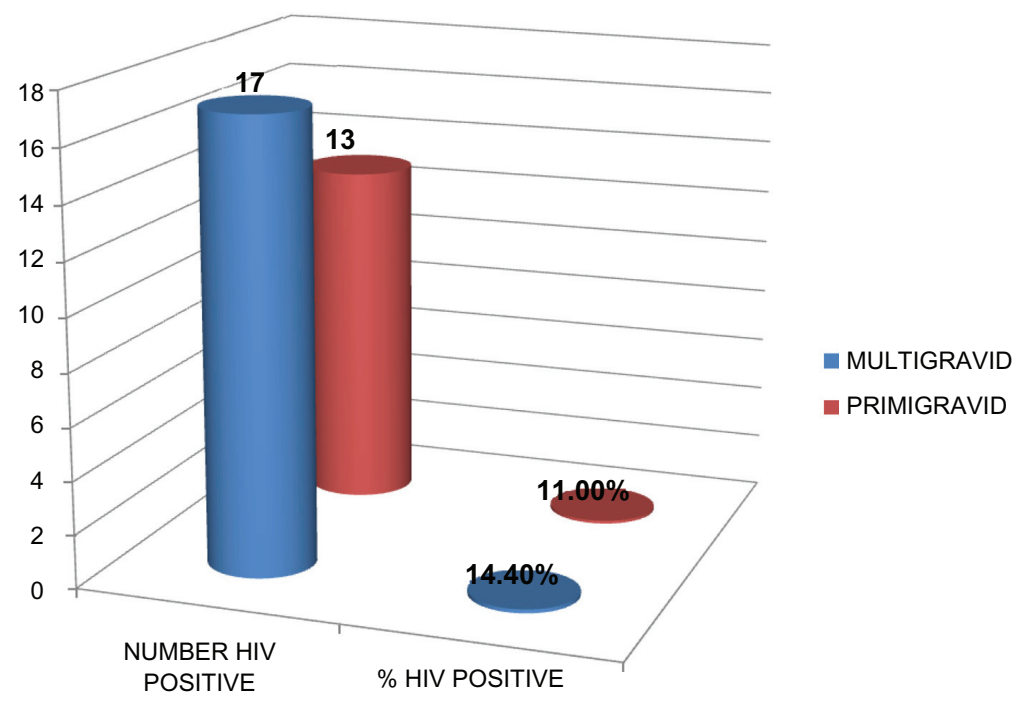

Figure 4 Prevalence of human immunodeficiency virus based on gravid status. 
body of evidence that prenatal care in pregnant women living with HIV improves perinatal as well as maternal outcomes, particularly in facilities where there is a comprehensive PMTCT program. Herbst et $\mathrm{al}^{17}$ examined the perinatal outcomes for women who had not accessed prenatal care and those who did. They found that not having any prenatal care increased the rate of preterm birth, low birth weight babies, and more morbidity for the mothers. Unbooked women had more cesarean sections for fetal distress, and their babies were more predisposed to respiratory distress, intraventricular hemorrhage, and death before discharge. A previous study in Port Moresby General Hospital, Papua, New Guinea, observed that unbooked mothers have a perinatal death rate which is four times that of those who attended antenatal clinics before their delivery. ${ }^{18}$ Similarly Treacy et $\mathrm{al}^{19}$ examined the outcomes of 101 unbooked women at the Rotunda Hospital in Dublin and observed that unbooked women had a significantly worse perinatal outcome. The unknown HIV status of this category of patients poses a risk not only to the patient, her baby, but also for the health staff caring for them in the peripartum period..$^{20}$ However, the baby is the most critical element in vertical transmission, and would invariably be left unattended and eventually add to the number of pediatric HIV patients, resulting in a heavy burden on their parents, health facilities, and the community.

The gestational age at presentation to hospital reflects the booking habits of this high-risk group of women who appear or present to the labor ward after a failed attempt at home delivery with the help of traditional birth attendants. Most of the patients had a spontaneous vaginal delivery, having being admitted in established labor. This trend leaves little or no time for antiretroviral therapy to be administered under the PMTCT program, with the hope of reducing transmission. This trend also exposes surgeons, nurses, and midwives to the possible risk of transmission. Counseling and detection of pregnant women infected with HIV is a difficult issue, particularly in low resource settings where there is a high tendency for out-of-hospital births, home births, and other parallel nonhospital-based antenatal care. ${ }^{21}$

In this study, the seroprevalence rate amongst unbooked women was significantly higher than in booked patients in previous studies. These findings are very pertinent to health care delivery in our environment, because a critical number of unbooked patients may not be benefiting from the PMTCT program, thus increasing the pediatric HIV burden in our environment. There is the need to develop innovative ways to engage with these hard to reach groups who may not access conventional antenatal services, by engaging in widespread community health education to raise awareness of voluntary counseling and testing, antenatal care, and the PMTCT program.

\section{Acknowledgments}

We thank Professor Chris Akani, Consultant Gynecologist, the staff of the isolation ward at the University of Port Harcourt Teaching Hospital, and all the pregnant women who consented to being part of this study, for their collaboration.

\section{Disclosure}

The authors report no conflicts of interest in this work.

\section{References}

1. Carroli G, Rooney C, Villar J. How effective is antenatal care in preventing maternal mortality and serious morbidity? An overview of the evidence. Paediatr Perinat Epidemiol. 2001;15(1):1-42.

2. Uniting the World against AIDS Report on the global AIDS epidemic 2008. Available at: http://www.unaids.org/en/KnowledgeCentre/HIVData/ GlobalReport/2008/2008_Global_report.asp. Accessed Aug 11, 2010.

3. Summary finding from the 2003 HIV/syphilis sentinel seroprevalence survey in Nigeria. Information for Policy Makers. 2003;30-50.

4. de Cock KM, Fowler MG, Mercier E, et al. Prevention of motherto-child HIV transmission in resource-poor countries: Translating research into policy and practice. JAMA. 2000;283(9):1175-1182

5. Mother-to-child transmission of HIV infection in the era of highly active antiretroviral therapy. Clin Infect Dis. 2005;40(3):458-465.

6. World Health Organization. Rapid advice: Revised WHO principles and recommendations on infant feeding in the context of HIV.2009. Available at: http://whqlibdoc.who.int/publications/2009/9789241598873_eng.pdf. Accessed Aug 11, 2010.

7. Stanton CK, Holtz SA. Levels and trends in caesarean birth in the developing world. Stud Fam Plann. 2006;37(1):41-48.

8. Napravnik RN, Royce R, Walter E, Lim W. HIV-1 infected women and prenatal care utilization: Barriers and facilitators. AIDS Patient Care STDS. 2000;14(8):411-420.

9. Erci B. Barriers to utilization of prenatal care services in Turkey. J Nurs Scholarsh. 2003;35(3):269-273.

10. Sword W. Prenatal care use among women of low income: A matter of taking care of self. Qual Health Res. 2003;13(3):319-332.

11. Dwyer C, Cooke H, Hort K. Bringing accessible antenatal care to disadvantaged women in outer Western Sydney. Aust J Primary Health. 2003;10(3):67-75.

12. Delvaux T, Buekens P, Godin I, Bousten M. Barriers to prenatal care in Europe. Am J Prev Med. 2001;21(1):52-59.

13. Shaffer CF. Factors influencing the access to prenatal care by Hispanic pregnant women. J Am Acad Nurse Pract. 2002;14(2):93-96.

14. Tsianakas V, Liamputtong P. What women from an Islamic background in Australia say about care in pregnancy and prenatal testing. Midwifery. 2002;18(1):25-34.

15. Tandon SD, Parillo KM, Keefer M. Hispanic women's perceptions of patient-centeredness during prenatal care. A mixed-method study. Birth. 2005;32(4):312-317.

16. Smith D, Edwards N, Varcoe C, Martens PJ, Davies B. Bringing safety and responsiveness into the forefront of care for pregnant and parenting Aboriginal people. ANS Adv Nurs Sci. 2006;29(2):E27-E44.

17. Herbst M, Mercer B, Beazley D, Meyer N, Carr T. Relationship of prenatal care and perinatal morbidity in low-birth weight infants. Am J Obstet Gynecol. 2003;189(4):930-933.

18. Failing F, Ripa P, Tefuarani N, Vince J. A comparison of booked and unbooked mothers delivering at the Port Moresby General Hospital: A case-control study. P N G Med J. 2004;47(3-4):174-180. 
19. Treacy A, Byrne P, O’Donovan M. Perinatal outcome in unbooked women at Rotunda Hospital. Irish Med J. 2002;95(2):44-47.

20. The International Perinatal HIV Group. The mode of delivery and the risk of MTCT of human immunodeficiency virus type 1. A meta analysis of 15 prospective cohort studies. $N$ Engl J Med. 1999;340:977-987.
21. The Voluntary HIV Counseling and Testing Efficacy Study Group. Efficacy of voluntary HIV counseling and testing in individuals and couples in Kenya, Tanzania and Trinidad. A randomized trial: Lancet. 2000;356(9224):103-112.

\section{Publish your work in this journal}

HIV/AIDS - Research and Palliative Care is an international, peerreviewed open-access journal focusing on advances in research in HIV, its clinical progression and management options including antiviral treatment, palliative care and public healthcare policies to control viral spread. The journal welcomes original research, basic science, clinical \& epidemiological studies, reviews \& evaluations, expert opinion \& commentary, case reports \& extended reports. The manuscript management system is completely online and includes a very quick and fair peer-review system. Visit http://www.dovepress.com/ testimonials.php to read real quotes from published authors.

Submit your manuscript here: http://www.dovepress.com/hivaids---research-and-palliative-care-journal 